\title{
Anti-inflammatory and Antimicrobial Potential of Cissus quadrangularis-Assisted Copper Oxide Nanoparticles
}

\author{
S. Rajeshkumar ${ }^{\mathbb{D}},{ }^{1}$ Soumya Menon, ${ }^{2}$ Venkat Kumar S, ${ }^{2}$ M. Ponnanikajamideen, ${ }^{3}$ \\ Daoud Ali, ${ }^{4}$ and Kalirajan Arunachalam $\mathbb{1 0}^{5}$ \\ ${ }^{1}$ Nanobiomedicine Lab, Department of Pharmacology, Saveetha Dental College and Hospitals, SIMATS, 600077, Chennai, India \\ ${ }^{2}$ Department of Biotechnology, School of Biosciences and Technology, VIT, Vellore 632014, India \\ ${ }^{3}$ Department of Pharmacology and Toxicology, University of Mississippi Medical Centre, Jackson, Mississippi, USA \\ ${ }^{4}$ Department of Zoology, College of Science, King Saud University, PO Box 2455, Riyadh 11451, Saudi Arabia \\ ${ }^{5}$ Department of Science and Mathematics, School of Science, Engineering and Technology, Mulungushi University, \\ Kabwe 80415, Zambia
}

Correspondence should be addressed to S. Rajeshkumar; ssrajeshkumar@hotmail.com

Received 7 October 2021; Accepted 30 November 2021; Published 27 December 2021

Academic Editor: Arpita Roy

Copyright (c) 2021 S. Rajeshkumar et al. This is an open access article distributed under the Creative Commons Attribution License, which permits unrestricted use, distribution, and reproduction in any medium, provided the original work is properly cited.

\begin{abstract}
Recently, nontoxic origin-mediated synthesis of copper oxide nanoparticles acquires further recognition because of the key role of bioapplications. The plant Cissus quadrangularis is one most prominent herbs used in the treatment of diabetes, asthma, tissue regeneration, etc. In this study, we tested the process of copper oxide nanoparticle synthesis and their role in many functions from Cissus quadrangularis. The synthesis of copper oxide nanoparticles uses plant extract and characterization by X-ray diffraction, thermogravimetric analysis (TGA), Fourier-transform infrared spectroscopy (FT-IR), atomic force microscope (AFM), and scanning electron microscope (SEM). The synthesized nanoparticles were analyzed for their biomedical applications such as antibacterial, antifungal, antioxidant, antidiabetic, and anti-inflammatory activity and antiproteinase action. The results show that the $C$. quadrangularis plant-mediated nanoparticles may be used in many biomedical applications related to arthritis, diabetes, and the production of various antimicrobial products in the future.
\end{abstract}

\section{Introduction}

The biosynthesis of nanoparticles is the collaboration of both fields of biotechnology and nanotechnology which involves biomaterials commonly used for the synthesis due to various advantages, but most importantly is due to its environment friendly nature [1].The importance of green nanotechnology has become a latest trend among the researchers lately, as it does not require any utilization of hazardous chemical or reagents; these reducing or stabilizing agents are nontoxic, biocompatible to the environment as well as for any biomedical applications. These agents include microorganisms, parts of plants, enzymes, or green chemicals like chitosan [2], curcumin [3], and chitin [4]. Copper nanoparticles are slightly toxic in nature. To curb in toxicity sulfidation of CuNP can be performed to form copper oxide nanoparticles [5]. Copper sulfide is an interesting area of research because of its ability to mould into various morphologies; it is a member of transition metal chalcogenides, and behaves like a p-type semiconductor where copper vacancies act as acceptor sites like digenite $\left(\mathrm{Cu}_{1.8} \mathrm{~S}\right)$, sulphur rich covellite $(\mathrm{CuS})$, copper rich chalcocite $\left(\mathrm{Cu}_{2} \mathrm{~S}\right)$, anilite $\left(\mathrm{Cu}_{1.75} \mathrm{~S}\right)$, or djurleite $\left(\mathrm{Cu}_{1.95} \mathrm{~S}\right)$. The ability to form nonstoichiometric phases is because of the variable valence states of copper which has a formula of $\mathrm{Cu}_{\mathrm{x}} \mathrm{S}_{\mathrm{y}}$ [6,7]. Various methods have been employed for the synthesis of these nanoparticles like laser induction [8], pulse laser ablation [9], solvothermal [10], phase-controlled synthesis [11], sonochemical [12], or electrobiosynthesis [13]. The major setback of these mentioned methods is the requirement of 


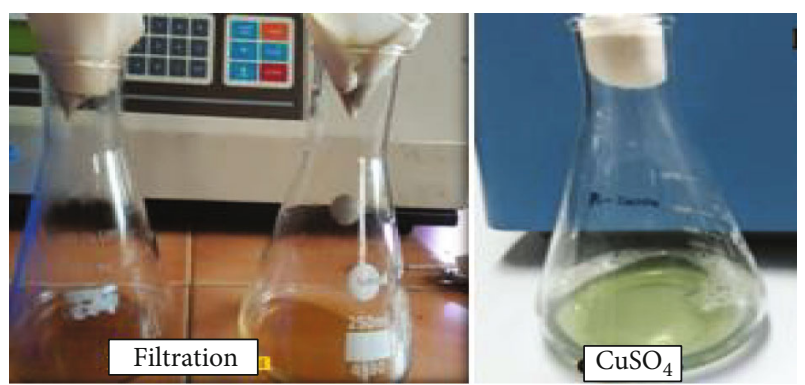

FIGURE 1: Synthesis of copper oxide nanoparticles using plant extract.

complicated or expensive equipment and external usage of stabilization agents along with reducing agents. This can result in irregular impact in our surroundings; therefore, the utilization of phytochemicals from plants can be better alternative to this issue, which can act as both reducing and capping agent [14].

The antimicrobial evaluation is important to be considered as it has become a major threat to human via contaminated water or food. The demand for disinfectants has increased tremendously, then protection against food contamination which can be done by packaging, or the development of antibiotics that can be used against pathogenic agents or new formulation against multidrug-resistant (MDR) pathogens [15]. Oxidative stress is caused due to high generation of ROS, which may lead to chronic inflammation; therefore, production of antiinflammatory agents that can act as antioxidant agents which reduces the oxidative stress caused is also mandatory now [16].

This paper suggests the exploitation of copper oxide nanoparticles using fresh leaves of Cissus quadrangularis through various biomedical applications like antimicrobial, antioxidant, and anti-inflammatory or analyzing the antiproteinase activity.

\section{Materials and Methods}

For the synthesis of nanoparticles, the fresh leaves of Cissus quadrangularis were collected from Vellore district. The doubled-distilled water was used for the entire experiments. All the reaction was completed with glassware washed and rinsed by distilled water and dried in hot air oven [17]. The filtration was done by Whatman No.1 filter papers.

2.1. Plant Details. Cissus quadrangularis in South Indian treebine is a climbing, foetid shrub. The outermost layer of the stem is blackish to reddish; division of stem is densely pubscent, swollen at node (hold one or more leaves), and 4 petals are present [18]. It acts as a drug for local tissue injury that is better remedy and relief from wound problems and swelling issues.

Herbal plants have medicinally important components in their various kinds of parts like stem and leaves [19]. The synthesis of nanoparticles by plants depends upon the nature of plant that is their phytochemical compounds, specific adaptation, and medicinal values. In this study, we report the eco-friendly and cost-effective green synthesis of
TABle 1: Phytochemicals screening of the plant extract Cissus quadrangularis.

\begin{tabular}{lcc}
\hline S/No. & Phytochemicals & Results \\
\hline 1 & Carbohydrates & Reddish colour \\
2 & Tannins & Greenish blue \\
3 & Flavonoids & Yellow \\
4 & Alkaloids & Greenish \\
5 & Anthraquinone & Pink \\
6 & Anthacyanaside & Negative \\
7 & Steroids & Red colour layer \\
8 & Terpenoids & Negative \\
9 & Saponins & Foam layer \\
\hline
\end{tabular}

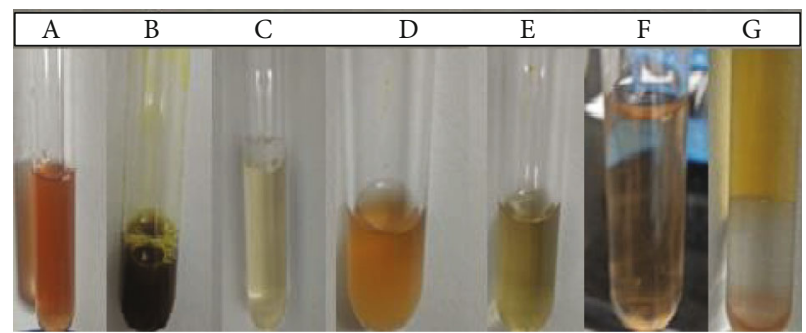

FIgURE 2: Phytochemical screening of plant extract Cissus quadrangularis.

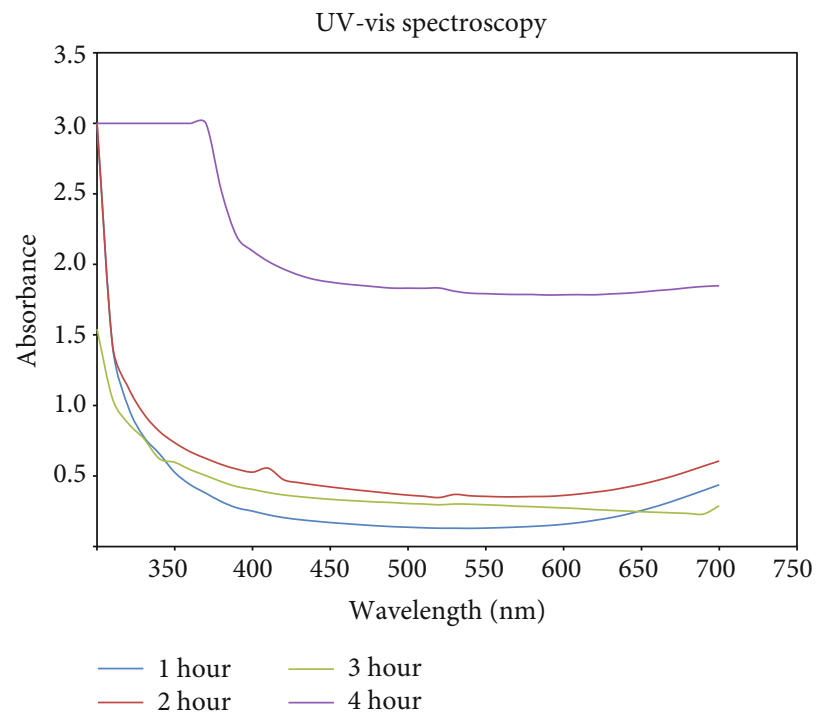

FIgURE 3: C. quadrangularis-mediated synthesis of copper oxide nanoparticles.

copper oxide nanoparticle using leaf extract of Cissus quadrangularis.

Botanical name: Cissus quadrangularis

Family: VITACEAE (grape family)

2.2. Preparation of Plant Extract. The fresh Cissus quadrangularis leaves were collected and thoroughly washed several times using normal water. Then, it was allowed to dry 
TABle 2: Particle sizes of nanoparticles by Debye-Scherrer equation.

\begin{tabular}{lccc}
\hline Samples & 2 theta & Crystalline size & Particles size \\
\hline C. quadrangularis-mediated synthesis of CuO NPs & 32.61 & 0.192 & $43 \mathrm{~nm}$ \\
\hline
\end{tabular}

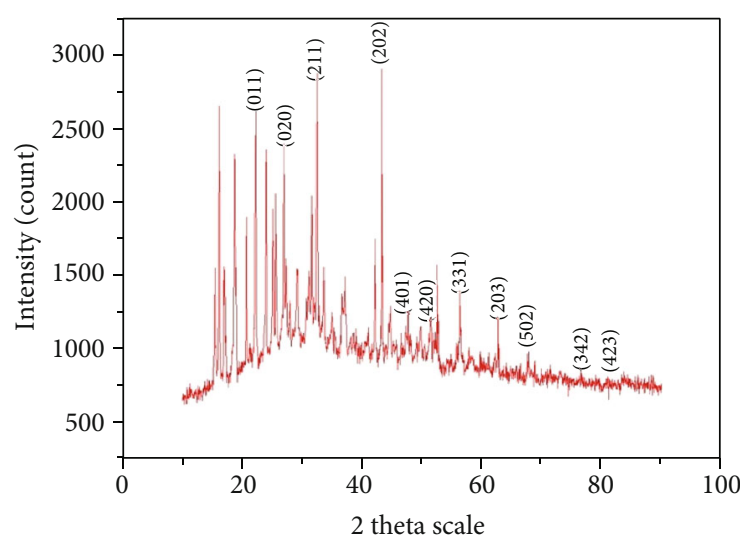

FIGURE 4: XRD patterns of plant-mediated synthesis of copper oxide nanoparticles.

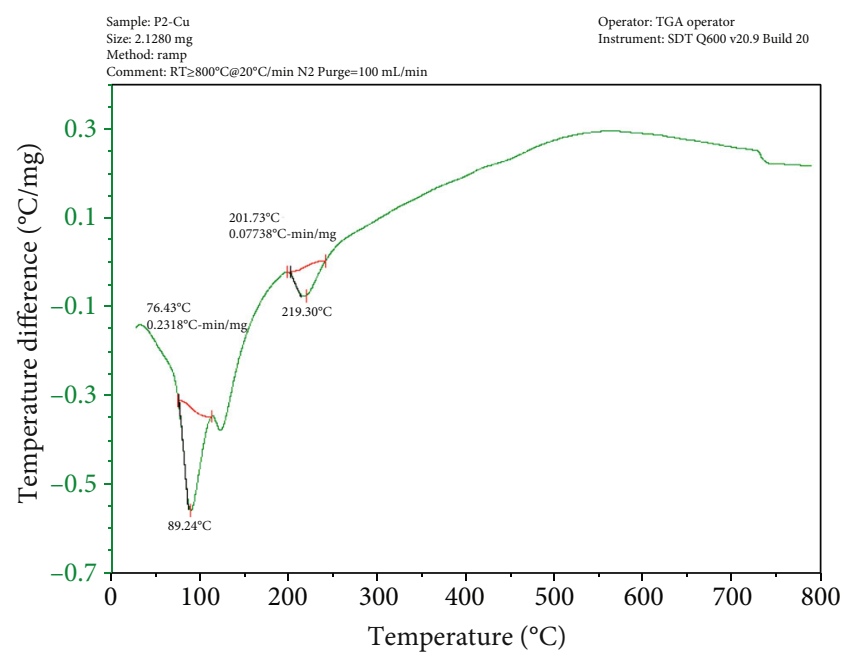

Figure 5: Data curve of copper oxide nanoparticles by Cissus quadrangularis.

sunshades. The dried leaves were grained as fine powder [17]. This plant powder was used for the further process of synthesis of nanomaterials.

2.3. Phytochemical Screening of Plant Extract. Medicinal plants are the richest biosource of drugs of traditional system, pharmaceuticals, neutraceuticals and food source, and chemical synthetic drugs. Extraction is the separation of medicinal active parts and tissues of plants with using of solvents by standard procedure [17]. The plant extracts and methanolic, ethanolic solvents were assessed for the phytochemical screening of carbohydrates, tannis saponins, flavonoid, alkaloids, anthraquinone, anthocyanside, steroids, and terpenoids by using standard methods.

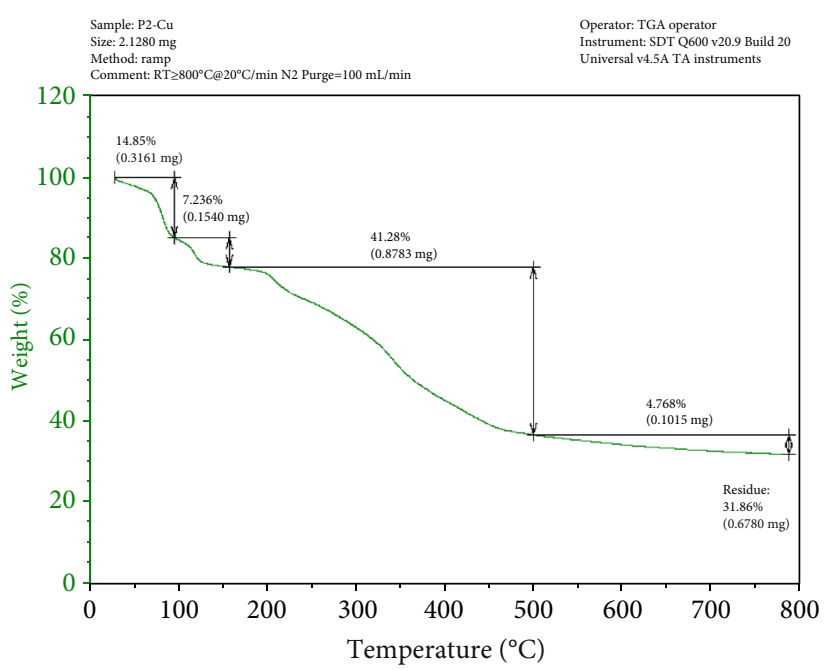

Figure 6: TGA curve of copper oxide nanoparticles by Cissus quadrangularis.

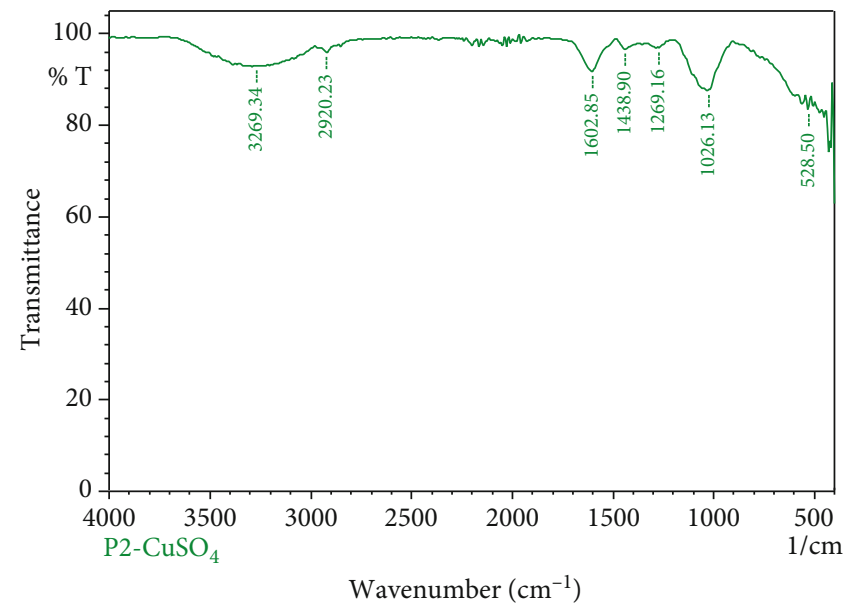

FIgURE 7: Cissus quadrangularis-mediated synthesis of copper oxide nanoparticles.

2.4. Synthesis of Plant-Mediated Nanoparticles. The fine dried powder of Cissus quadrangularis extract were used for the synthesis. $1 \mathrm{~g}$ of plant powder was dissolved in $100 \mathrm{~mL}$ of double-distilled water and kept for boiled in oven 2 minutes. This mixture was filtered by Whatman filter paper. The $20 \mathrm{~mL}$ of filtered solution was mixed with $80 \mathrm{~mL}$ of distilled water [20]. Then, $10 \mathrm{mM}$ of copper sulphate was added to this mixture and kept in shaker for 24 hours. After incubation, the solution was centrifuged for 10 minutes at $10000 \mathrm{rpm}$. Then, the pellet was collected and dried by hot air oven as shown in Figure 1 [17]. 

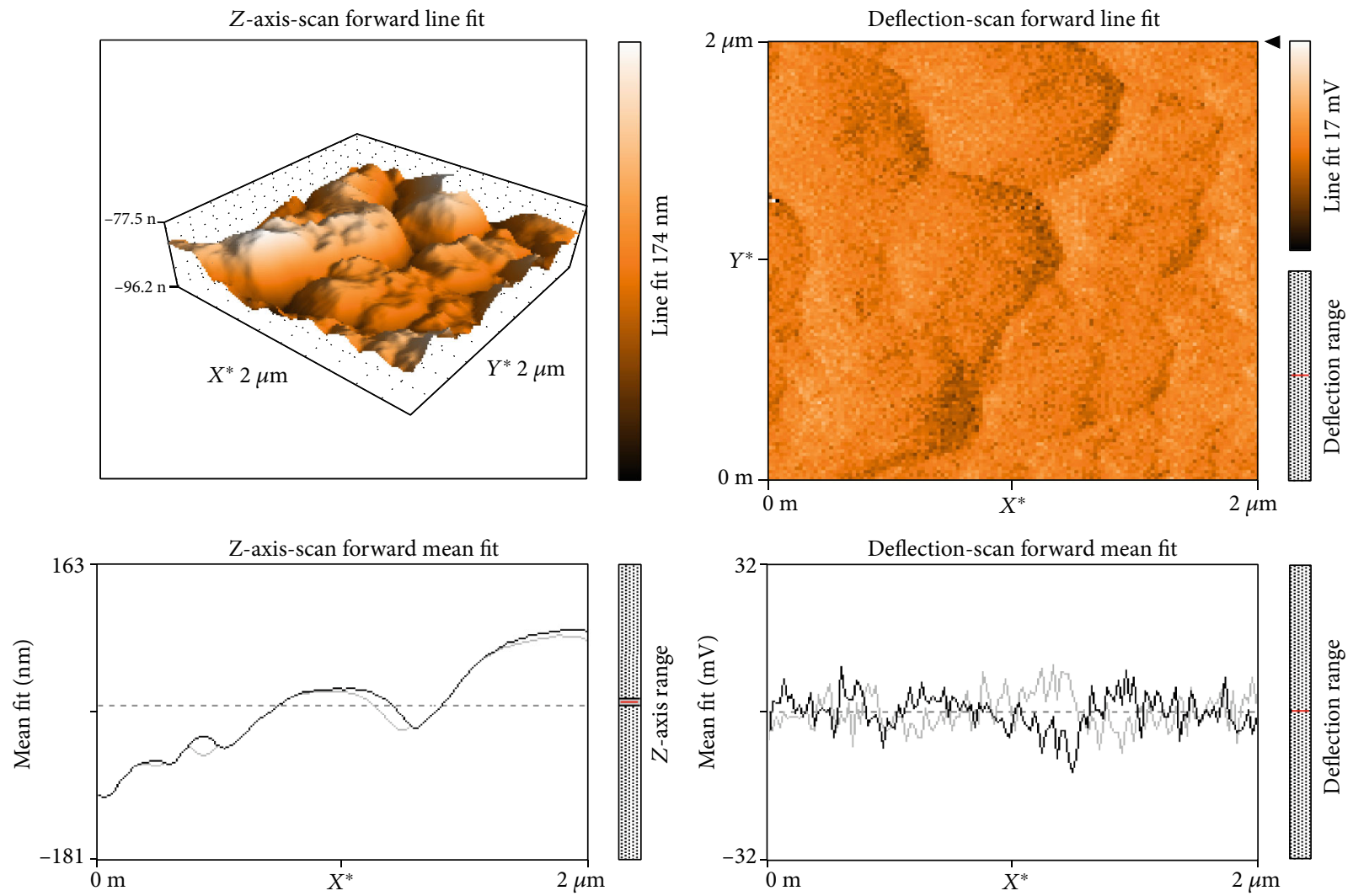

Figure 8: AFM data for C. quadrangularis-mediated copper oxide NPs.
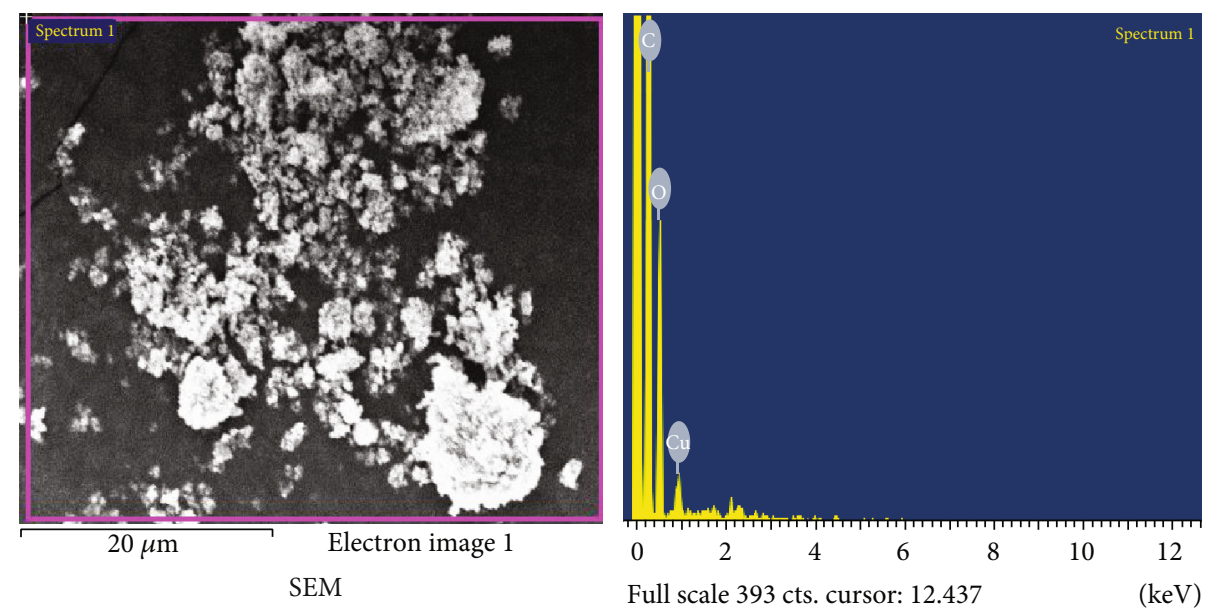

EDX

FIGURE 9: SEM and EDAX data for C. quadrangularis-mediated copper oxide NPs.

2.5. Characterization. Characterization is essential to determine the average size, shape, and features of the synthesised nanoparticles. These bioactive nanomaterials are analysed by $\mathrm{UV}$-Vis spectrophotometer, X-ray diffraction (Bruker-D8 advance, Germany model), thermogravimetric analysis (SDT Q600 V20.9 build 20), Fourier-transform infrared spectroscopy (FT-IR), atomic force microscope (AFM), and scanning electron microscope (SEM) [21].
TABLE 3: Antibacterial activity against plant-mediated synthesis $\mathrm{CuO}$ NPs.

\begin{tabular}{lccc}
\hline Clinical isolates & $\mathrm{Ab}$ & $\mathrm{Ab}+\mathrm{NP}$ & $\mathrm{NP}$ \\
\hline Staphylococcus aureus & 16 & 21 & 11 \\
Streptococcus sp. & 15 & 18 & 26 \\
Seratia marscenes & 8 & 10 & 20 \\
Escherichia coli & 25 & 26 & $\mathrm{R}$ \\
\hline
\end{tabular}




\subsection{Applications}

2.6.1. Antibacterial-Enhanced Method. Antimicrobial activity of copper oxide-mediated synthesis of nanoparticle acts against pathogenic bacterial strains (Staphylococcus aureus, Streptococcus, E. coli, and Serratia marcesecens [17]). To determine the zone of inhibition was observed using MHA agar [22]. Muller Hinton agar was prepared and sterilized at $120 \mathrm{lbs}$ for 45 minutes. Media were poured on the respective plates; after solidification, the disc was placed and kept for incubation at $37^{\circ} \mathrm{C}$ for 24 hours. After incubation, the zone of inhibition was measured [23].

2.6.2. Antifungal Activity. Antifungal activity of biosynthesised copper oxide nanoparticle was determined against four fungal strains (Candida albicans, Aspergillus niger, Aspergillus flavus, Aspergillus aculeatus). This action was done by disc diffusion method using potato dextrose agar [24]. Pour the sterilized media on the plates allowed to solidification. The disc was placed on the plates and kept for incubation at $25^{\circ} \mathrm{C}$ for 48 hours after treated with UV radiation [25].

2.6.3. Antioxidant Activity. Antioxidant activity was performed by DPPH (1,1diphynyl-2 picryl hydrazyl) assay to $\mathrm{CuO}$ nanoparticle [26]. Antioxidants play a major role in health protecting factor; it is reducing the chronic disorders [27]. This method gives the antioxidants possible potential of quadrangularis-mediated synthesis of NPs. Free radical scavenging activity of different concentration $(50 \mu \mathrm{g} / \mathrm{mL}$, $100 \mu \mathrm{g} / \mathrm{mL}, 150 \mu \mathrm{g} / \mathrm{mL}$, and $200 \mu \mathrm{g} / \mathrm{mL}$ ) of nanoparticles by $0.01 \mathrm{Mm}$ of DPPH $(39.432 \mathrm{~g} / \mathrm{mol})$ were prepared dissolved in ethanol [27]. The prepared DPPH solution was incubated for 30 minutes at dark place. Then, solution $(2 \mathrm{~mL})$ was added to the different concentration NPs, and $2 \mathrm{~mL}$ of ethanol was added and incubated for 30 minutes. The reference standard (positive control) compound being used was ascorbic acid, the absorbance measured at $517 \mathrm{~nm}$ [28].

2.6.4. Antidiabetic Activity. Diabetes mellitus is a chronic disorder which leads to severe tissue damage and vascular damage due to insulin sufficient. The herbal products are playing major role in drug development [29]. Here, the Cissus quadrangularis-mediated synthesis of NPs was used to determine the efficiency against diabetes characterized by alpha amylase activity. To take the different concentrations of NPS $(50 \mu \mathrm{g} / \mathrm{mL}, 100 \mu \mathrm{g} / \mathrm{mL}, 150 \mu \mathrm{g} / \mathrm{mL}$, and $200 \mu \mathrm{g} / \mathrm{mL})$, add the $500 \mu \mathrm{L}$ of phosphate buffer containing alpha amylase $(0.5 \mathrm{mg} / \mathrm{mL})$ solution. The mixture was incubated for 10 minutes at RT. Then, $500 \mu \mathrm{L}$ of $1 \%$ starch-containing phosphate buffer solution was incubated for 10 minutes. Then, add the $1 \mathrm{~mL}$ of DNSA (containing $0.5 \mathrm{~g}$ of dinitro salicylic acid, $15 \mathrm{~g}$ of sodium potassium tartrate diluted in $50 \mathrm{~mL}$ of distilled water). It was kept for 5 minutes in water bath [29]. The reaction mixtures make up into $5 \mathrm{~mL}$ of distilled water, and optical density was observed at $540 \mathrm{~nm}$.

2.6.5. Anti-inflammatory Activity. Inflammation in biological response from damage cells (local tissue injury) is a difficult response that prevent the tissue damage and invasion of microbes through the small cuts, scratch, and abrasions [30].
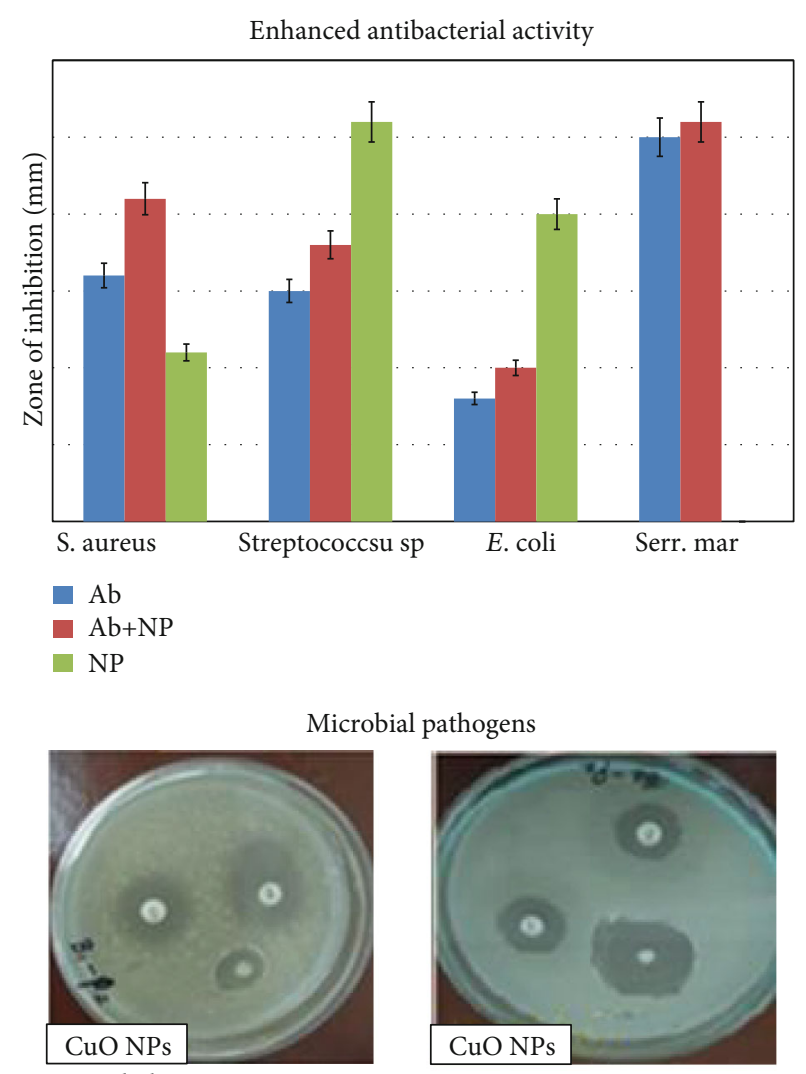

Staphylococcus aureus
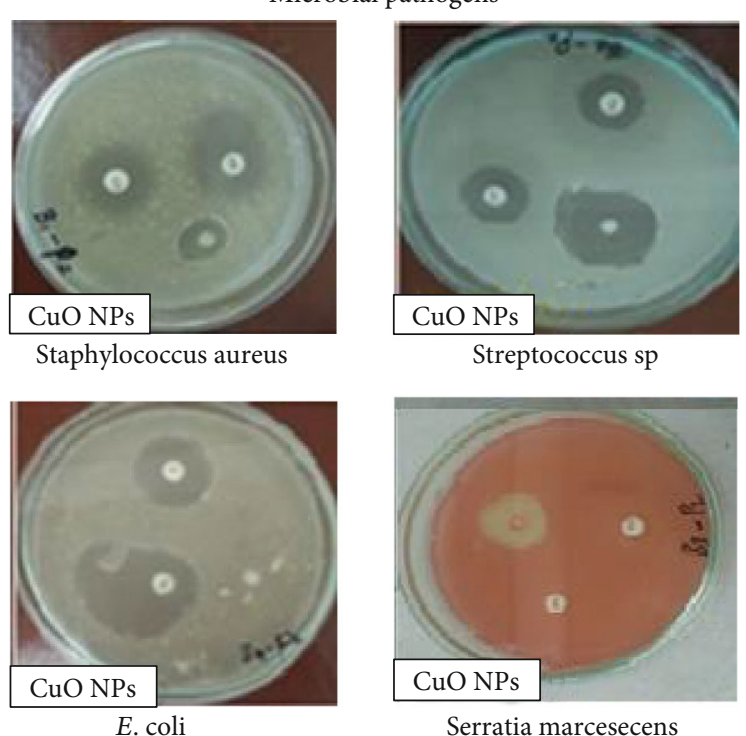

FIgURE 10: Antibacterial activity of copper oxide nanoparticles against Staphylococcus aureus, Streptococcus, E. coli, and Serratia marcesecens.

TABLE 4: Antifungal activity against plant-mediated synthesis copper oxide NPs.

\begin{tabular}{lccc}
\hline Clinical isolates & $\mathrm{Ab}$ & $\mathrm{Ab}+\mathrm{NP}$ & $\mathrm{NP}$ \\
\hline Candia albicans & 7 & 22 & 17 \\
Aspergillus niger & 7 & 16 & $\mathrm{R}$ \\
Aspergillus flavus & 7 & 8 & $\mathrm{R}$ \\
Aspergillus aculeatus & 11 & 14 & $\mathrm{R}$ \\
\hline
\end{tabular}

The membrane stabilization assay was performed by $\mathrm{O}$ positive blood. $10 \mathrm{~mL}$ of blood were collected with equal volume of Alsever solution ( $1 \mathrm{~g}$ of dextrose, $0.8 \mathrm{~g}$ of sodium citrate, $0.025 \mathrm{~g}$ citric acid, and $0.21 \mathrm{~g}$ sodium chloride in $50 \mathrm{~mL}$ ) centrifuged at $3000 \mathrm{rpm}$, then the cells were separated and washed with isosaline $(0.9 \mathrm{~g}$ of Nacl in $100 \mathrm{~mL}$ of distilled 

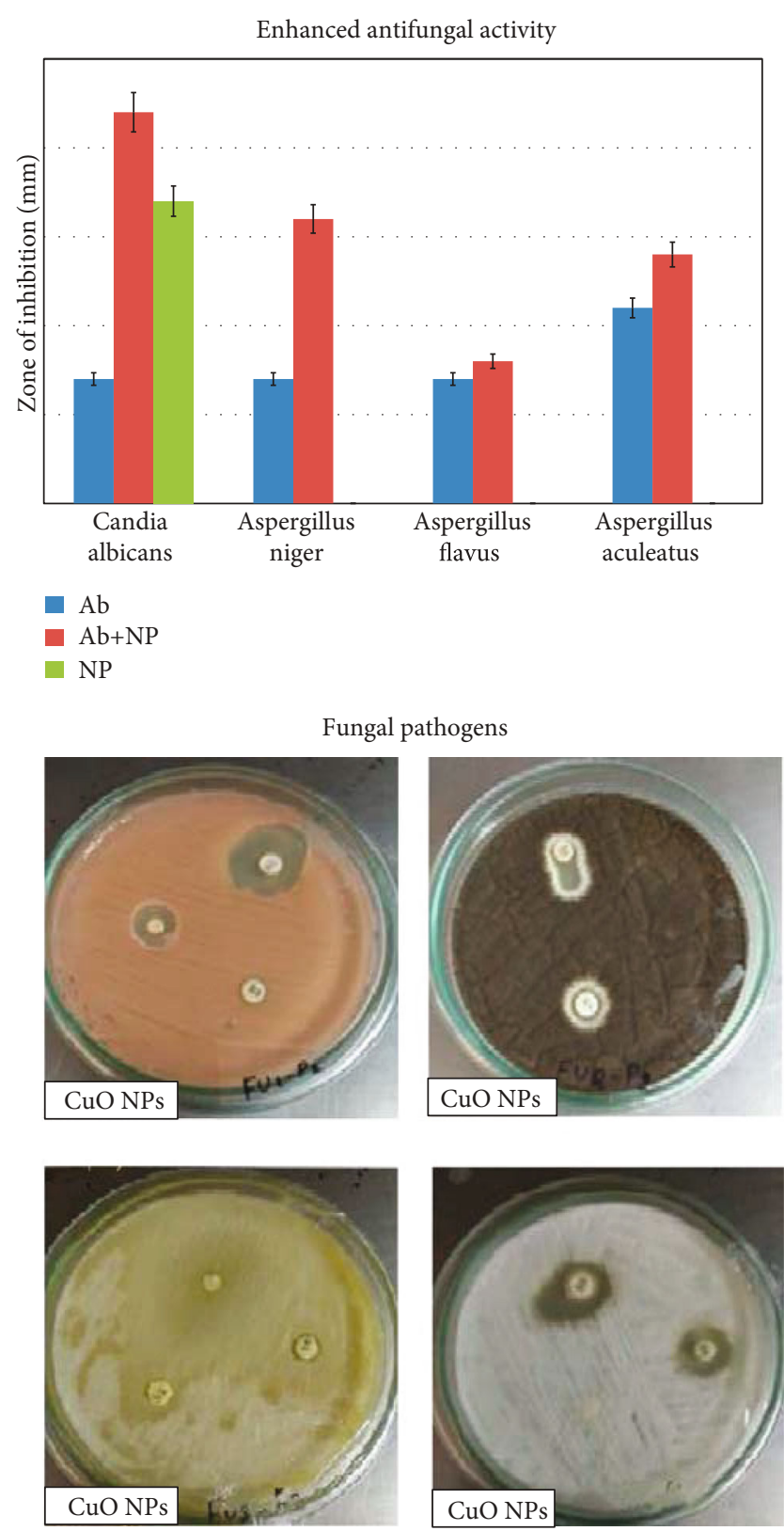

Figure 11: Antifungal activity of copper oxide nanoparticles.

water). Then, the different concentrations of NPs were mixed with HRBC $(0.5 \mathrm{~mL})$, phosphate buffer $(0.5 \mathrm{~mL})$, and $2 \mathrm{~mL}$ of hyphosaline $(0.4 \mathrm{~g} \mathrm{Nacl}$ in $100 \mathrm{~mL})$. The mixture of solution was incubated at $37^{\circ} \mathrm{C}$ for 30 minutes and centrifuged at $3000 \mathrm{rpm}$. Then, the absorbance of haemoglobin content was estimated at $560 \mathrm{~nm} \mathrm{[31].}$

2.6.6. Antiproteinase Action. The herbal-mediated synthesis of nanoparticle was studied for anti-inflammatory activity by antiproteinase action. The reaction mixture contains $0.06 \mathrm{mg}$ of trypsin, $1 \mathrm{~mL}$ of test $\mathrm{Mm}$ tris $\mathrm{Hcl}$ buffer, and different concentration $(50 \mu \mathrm{g} / \mathrm{mL}, 100 \mu \mathrm{g} / \mathrm{mL}, 150 \mu \mathrm{g} / \mathrm{mL}$, and $200 \mu \mathrm{g} / \mathrm{mL}$ ) of nanoparticle. These mixtures of solution were incubated at $37^{\circ} \mathrm{C}$ for 5 minutes [30]. After incubation $1 \mathrm{~mL}$ of $8 \%(W / V)$ casein was added and incubated for 20
TABLE 5: C. quadrangularis-mediated synthesis of CuNo4 NPs.

\begin{tabular}{lccccc}
\hline Concentration & Standard & Control & NPs & $\begin{array}{c}\text { Scavenging } \\
\text { activity }\end{array}$ & IC 50 \\
\hline $50 \mu \mathrm{g} / \mathrm{mL}$ & 0.084 & 0.934 & 0.245 & 73.76874 & \\
$100 \mu \mathrm{g} / \mathrm{mL}$ & 0.095 & 0.934 & 0.856 & 8.351178 & 264.69 \\
$150 \mu \mathrm{g} / \mathrm{mL}$ & 0.102 & 0.934 & 0.867 & 7.173448 & \\
$200 \mu \mathrm{g} / \mathrm{mL}$ & 0.108 & 0.934 & 0.871 & 6.745182 & \\
\hline
\end{tabular}

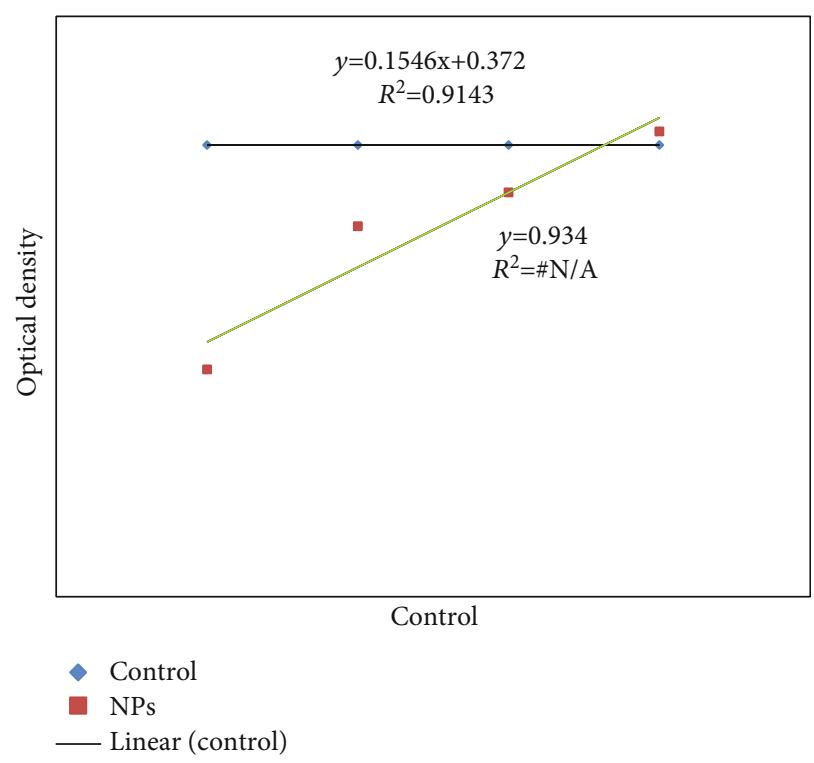

FIgURE 12: Antioxidant activity of copper oxide NPs.

minutes. The $2 \mathrm{~mL}$ of percholoric acid was added. The cloudy suspension were centrifuged, and the absorbance of nanoparticles were taken at $210 \mathrm{~nm}$ [32].

2.7. Statistical Analysis. All the data are represented as mean \pm SD. The standard one-way ANOVA was used for standardization with $p$ value $<0.05$ which is considered as statistically significant.

\section{Results and Discussion}

3.1. Phytochemical Screening. The collected plant material was analysed by the phytochemical screening to check the presence of amino acid like carbohydrates and other compounds. Table 1 and Figure 2 shows the positive and negative result of the plant extract.

\subsection{Characterization}

3.2.1. UV-Visible Spectrophotometer. The characterization of nanoparticles begins with the UV-Visible absorbance, which depends upon the principle of SPR (surface plasmon resonance), where the conducting electrons get excited, and the absorbance is measured. The absorbance of nanomaterials observed ranges between the 300 and $700 \mathrm{~nm}$. In this case, the copper ions reduced to nanoparticulate forms using the extract of Cissus quadrangularis. The reaction time taken was $4 \mathrm{~h}$ with maximum absorbance of $340 \mathrm{~nm}$ as shown in Figure 3 [22]. 
TABLE 6: C. quadrangularis-mediated synthesis of copper oxide NPs.

\begin{tabular}{|c|c|c|c|c|c|c|c|}
\hline Concentration & I & II & III & MEAN & STD DEV & STD ERR & Final \\
\hline $50 \mu \mathrm{g} / \mathrm{mL}$ & 1.286 & 1.334 & 1.378 & 1.33 & 0.046014 & 0.03 & $11.07 \pm 0.21$ \\
\hline $100 \mu \mathrm{g} / \mathrm{mL}$ & 2.055 & 2.145 & 2.223 & 2.14 & 0.084071 & 0.05 & $11.07 \pm 0.22$ \\
\hline $150 \mu \mathrm{g} / \mathrm{mL}$ & 2.257 & 1.278 & 1.345 & 1.63 & 0.546912 & 0.32 & $11.07 \pm 0.23$ \\
\hline $200 \mu \mathrm{g} / \mathrm{mL}$ & 3.157 & 3.234 & 3.279 & 3.22 & 0.061695 & 0.04 & $11.07 \pm 0.24$ \\
\hline
\end{tabular}
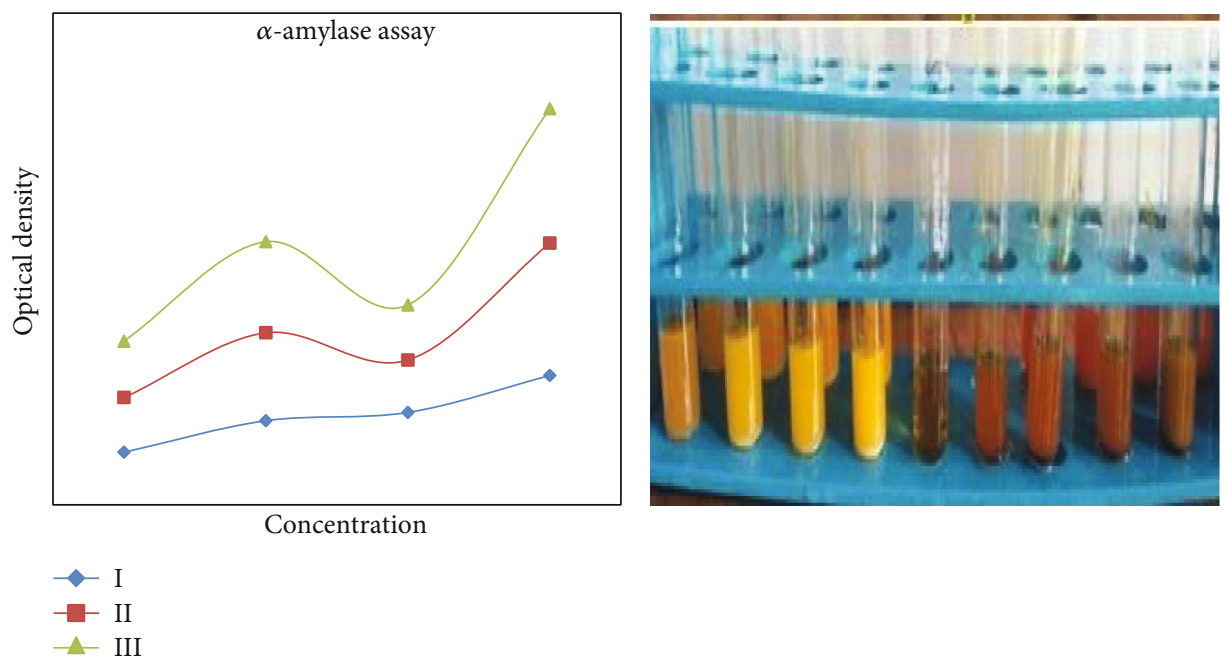

Concentration

FIgURe 13: Antidiabetic activity of copper oxide NPs.

3.2.2. X-Ray Diffraction Analysis. The size of the nanoparticles was calculated according to these peak values and crystalline size [33]. The synthesised herbal and fungal nanoparticles by copper sulfide size were found by the Debye-Scherrer equation from the $2 \theta$ values and crystalline size from Table 2 and Figure 4.

$$
\begin{aligned}
D= & k \lambda / B \cos \theta(\text { Particle Size }=(0.9 \times \lambda) /(d \cos \theta) \\
K= & 0.9(\text { constant }): \lambda=1.54060(\text { constant }) ; 2 \theta=29.72 ; \\
\theta= & 12.86 ; B=0.187=0.9 \times 1.5406 \times 10-{ }^{10} / 0.187 \\
& \times \cos 12.86 \times 0.01744 \\
D= & 42 \mathrm{~nm} B=\text { Full width half maximum }(\text { radian })
\end{aligned}
$$

3.2.3. TGA Analysis. From this result, to evaluate the loss of weight and peak of the temperature was observed [34, 35]. To find the weather, the nanoparticles increase or decrease their weight by TGA. The analysis of room temperature was observed from $800^{\circ} \mathrm{C}$. The differential thermal analysis shows the (CuO-plant) $2.2060 \mathrm{mg}$ ranges for synthesised materials. The thermal gravimetric analysis gave the weight loss of material at a particular temperature as shown in Figures 5 and 6.

3.2.4. Fourier-Transform Infrared Spectroscopy. The functional groups of Cissus quadrangularis plant-mediated synthesis of copper oxide nanoparticles is $3269.34 \mathrm{~cm}^{-1} \mathrm{~N}-\mathrm{H}$ stretch band due to presence of amine group. This primary amine produces two N-H absorptions, $2920.23 \mathrm{~cm}^{-1}$ belongs
TABLE 7: C. quadrangularis-mediated synthesis of copper oxide NPs.

\begin{tabular}{lcc}
\hline Concentration & Standard & NPs \\
\hline $50 \mu \mathrm{g} / \mathrm{mL}$ & 1.22 & 0.649 \\
$100 \mu \mathrm{g} / \mathrm{mL}$ & 2.403 & 0.198 \\
$150 \mu \mathrm{g} / \mathrm{mL}$ & 2.311 & 0.248 \\
$200 \mu \mathrm{g} / \mathrm{mL}$ & 2.363 & 0.246 \\
\hline
\end{tabular}

to alkene group (C-H bond), and $1602.85 \mathrm{~cm}^{-1}$ and $1438.90 \mathrm{~cm}^{-1}$ have an aromatic compounds ( $\mathrm{C}=\mathrm{C}$ bond). From this analysis, it is suggested that antioxidant enzymes with amines, ethyl Ester, aromatic compounds, alkenes, and acetic acids might be absorbed on biosynthesized copper oxide nanoparticle as shown in Figure 7.

3.2.5. Atomic Force Microscope. Figure 8 shows the AFM images and express their surface size such as for scanned area range of $C$. quadrangularis-mediated synthesis of copper oxide NPs 70 to $100 \mathrm{~nm}$. From this surface analysis, the particle size display the clusters of even line of profile [36].

3.2.6. Scanning Electron Microscope. It was observed $90 \mathrm{~nm}$ copper oxide nanoparticles synthesized using Cissus quadrangularis. The plant extracts exhibit different shapes of nanoparticles confirmed using SEM [37]. The presence of copper nanoparticle was confirmed by the EDX analysis, whereas the peaks gave the amount of particles in sample as shown in Figure 9. 


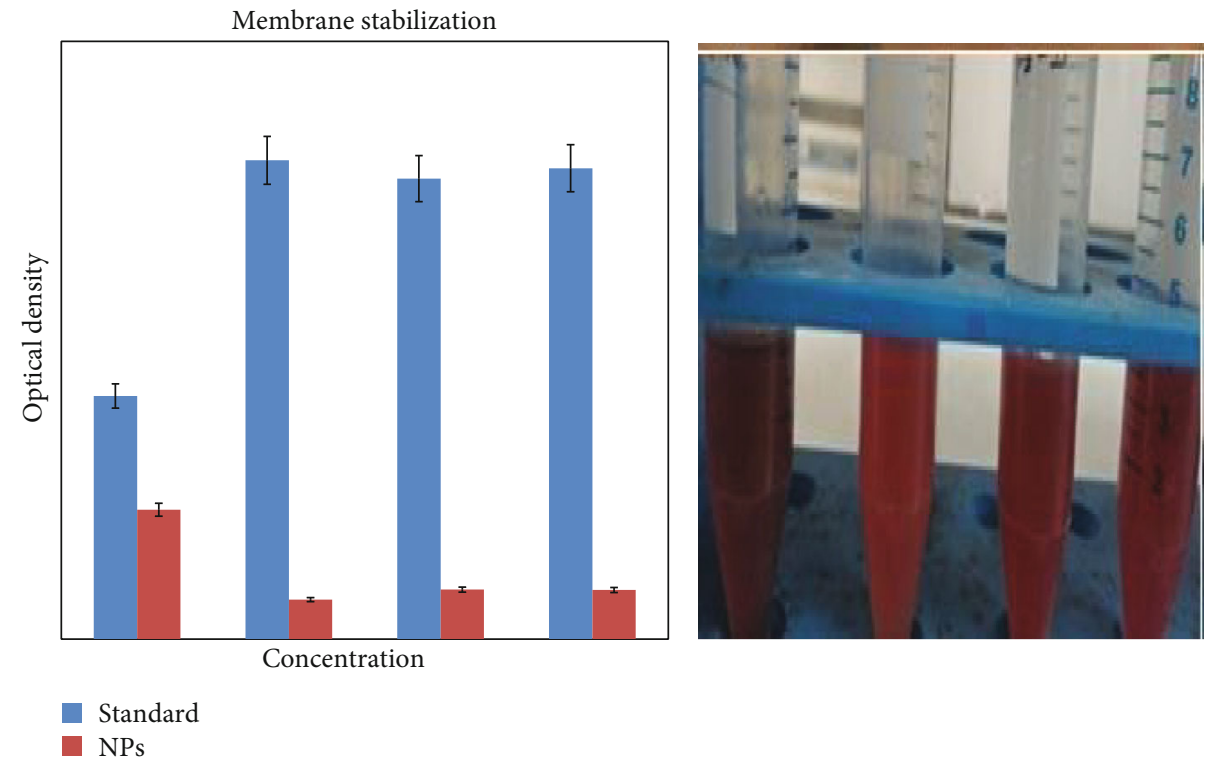

FIgURE 14: Anti-inflammatory activity of copper oxide NPs.

TABLE 8: C. quadrangularis-mediated synthesis of copper oxide nanoparticles.

\begin{tabular}{|c|c|c|c|c|c|c|c|}
\hline Concentration & I & II & III & MEAN & Std. dev & Std. err & Final \\
\hline $50 \mu \mathrm{g} / \mathrm{mL}$ & 1.426 & 1.467 & 1.521 & 1.47 & 0.047648 & 0.03 & $11.07 \pm 0.21$ \\
\hline $100 \mu \mathrm{g} / \mathrm{mL}$ & 1.836 & 1.895 & 1.921 & 1.88 & 0.043555 & 0.03 & $11.07 \pm 0.22$ \\
\hline $150 \mu \mathrm{g} / \mathrm{mL}$ & 2.422 & 1.491 & 1.567 & 1.83 & 0.516972 & 0.30 & $11.07 \pm 0.23$ \\
\hline $200 \mu \mathrm{g} / \mathrm{mL}$ & 3.191 & 3.245 & 3.456 & 3.30 & 0.140037 & 0.08 & $11.07 \pm 0.24$ \\
\hline
\end{tabular}

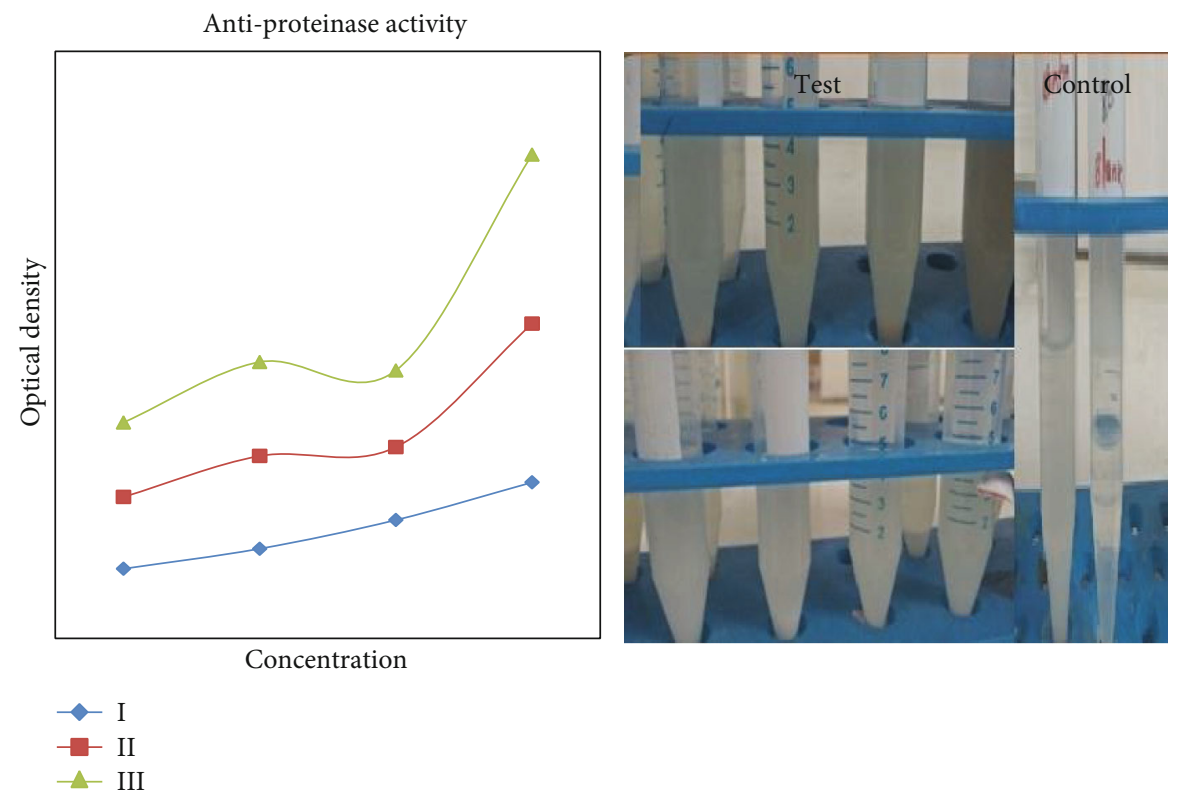

FIgURe 15: Antiproteinase activity of copper oxide NPs.

3.2.7. Antibacterial Activity. The antibacterial activity of the copper oxide nanoparticle was observed by the antibacterialenhanced method using control as streptomycin. Different formulations which involve the different mode of preparation or surface-decorated biomolecules of antimicrobial agents are produced which is cost effective, safe, and can also be treated against many MDR cultures [38]. The antibacterial activity was evaluated against Staphylococcus aureus, Streptococcus, 
E. coli, and Serratia marcesecens. The zone of inhibition measured between the three different modes such as in each space contains the antibiotic disc, antibiotic disc with nanoparticles, and nanoparticles. From the result, the nanoparticle copper oxide $(26 \mathrm{~mm})$ has a high effect against E. coli, the form of antibiotics with NPs as shown in Table 3 and Figure 10. The need to develop novel antibacterial agents has become an important task amongst researchers as a problem of resistance against bacterial cultures is being generated. The mechanism behind its antibacterial potential is explained by the interaction of the nanoparticles with outer surface of the cell membrane of the cultures, which eventually leads to disruption of the integrity of the membrane by producing pits in them, and increase of permeability causes a release of lipopolysaccharide molecules or other protein materials, and this results in cell death $[39,40]$.

3.2.8. Antifungal Activity. The antifungal activity of copper oxide NP against Candia albicans, Aspergillus niger, Aspergillus flavus, and Aspergillus aculeatus was executed; the result has a good antifungal agent. The green synthesised copper oxide nanoparticle acts as better antifungal agent compared to earlier report and commercially available standards as shown in Table 4 and Figure 11.

3.2.9. Antioxidant Activity. Antioxidant activity of copper oxide NP was determined by DPPH assay through the free radical scavenging activity. The ascorbic was used as a standard and methanol act as a negative control. From the calibration curve, the IC 50 values denoted the inhibition of concentration in scavenge $50 \%$ of the DPPH free radical activity as shown in Table 5 and Figure 12.

$$
\begin{aligned}
\text { Scavenging activity } & =\mathrm{A} 0-\mathrm{A} 1 / \mathrm{A} 0 \times 100 \\
\mathrm{~A} 0 & =\text { Absorbance of the control } \\
\mathrm{A} 1 & =\text { absorbance of the test sample } \\
Y & =0.153 x+0.362(m x+c) \\
\text { IC } 50 & =50-0.362 / 0.153 \\
Y & =324.42
\end{aligned}
$$

3.2.10. Antidiabetic Activity. Alpha amylase activity of copper oxide NP was assessed by the DNSA method. The triplicate values of amylase assay confirm the information in the measurement process which gave the mean of average the 3 values and standard deviation for exact variation in the samples of nanoparticles as shown in Table 6 and Figure 13.

3.2.11. Anti-inflammatory Activity. The anti-inflammatory activity of copper oxide NPs shows the values about the inhibition of the concentration. Stabilization of membrane will produce the various disorder related to the inflammation due to release of lysosomal enzymes (as shown in Table 7 and Figure 14).

3.2.12. Antiproteinase Action. Antiproteinase action is one of the assessments of anti-inflammatory activity. It played an important role in the tissue damage during the inflammation action. This analysis is done by triplicate, and the results were calculated through the mean and standard deviation to fine the variables between the samples as shown in Table 8 and Figure 15.

\section{Conclusion}

The nanoparticle screening confirms the presence of phytochemicals such as carbohydrates, saponins, tannins, flavonoid, alkaloids, and steroids. Characterization of NPs gave the structures and size for XRD evaluated by the DebyeScherrer formula, and for FTIR, the presence of functional group distinguishes by value of peaks. For microbial studies, the result of antibacterial and antifungal activities was observed by the zone of inhibition. Other potentials of copper oxide nanoparticles were also evaluated like antioxidant, antidiabetic, and anti-inflammatory activity and antiproteinase action. Therefore, the mechanism behind its action is yet to be researched, but these nanoparticles can also be an agent which fills the criteria of eco-friendly, nontoxic, and easy production in larger scale.

\section{Data Availability}

The data used to support the findings of this study are included within the article.

\section{Conflicts of Interest}

The authors declare that there is no conflict of interest.

\section{Authors' Contributions}

SR designed the research; and SR and SM carried out research; and SM, SV, MP, DA, and KA wrote and corrected the manuscript.

\section{Acknowledgments}

The authors would like to acknowledge Saveetha Dental College and Hospital, SIMATS, and the work was funded by Researchers Supporting Project number (RSP-2021/165), King Saud University, Riyadh, Saudi Arabia.

\section{References}

[1] A. I. El-Batal, N. E. Al-Hazmi, F. M. Mosallam, and G. S. ElSayyad, "Biogenic synthesis of copper nanoparticles by natural polysaccharides and_Pleurotus ostreatus_ fermented fenugreek using gamma rays with antioxidant and antimicrobial potential towards some wound pathogens," Microbial Pathogenesis, vol. 118, pp. 159-169, 2018.

[2] N. Ali, Awais, T. Kamal et al., "Chitosan-coated cotton cloth supported copper nanoparticles for toxic dye reduction," International Journal of Biological Macromolecules, vol. 111, pp. 832-838, 2018.

[3] M. Kumari, L. Ray, M. P. Purohit et al., "Curcumin loading potentiates the chemotherapeutic efficacy of selenium nanoparticles in HCT116 cells and Ehrlich's ascites carcinoma bearing mice," European Journal of Pharmaceutics and Biopharmaceutics, vol. 117, pp. 346-362, 2017. 
[4] K. T. Smitha, A. Anitha, T. Furuike, H. Tamura, S. V. Nair, and R. Jayakumar, "In vitro evaluation of paclitaxel loaded amorphous chitin nanoparticles for colon cancer drug delivery," Colloids Surfaces B Biointerfaces, vol. 104, pp. 245-253, 2013.

[5] S. Roy, J. W. Rhim, and L. Jaiswal, "Bioactive agar-based functional composite film incorporated with copper sulfide nanoparticles," Food Hydrocolloids, vol. 93, pp. 156-166, 2019.

[6] X. Huang, C. Xu, Y. Li, H. Cheng, X. Wang, and R. Sun, "Quaternized chitosan-stabilized copper sulfide nanoparticles for cancer therapy," Materials Science and Engineering: C, vol. 96, pp. 129-137, 2019.

[7] S. Yadav, K. Shrivas, and P. K. Bajpai, "Role of precursors in controlling the size, shape and morphology in the synthesis of copper sulfide nanoparticles and their application for fluorescence detection," Journal of Alloys and Compounds, vol. 772, pp. 579-592, 2019.

[8] A. Sharma, A. Yadav, S. K. Sharma, and R. K. Sharma, "Laser induced morphology change in copper sulphide nanoparticles," Colloids and Surfaces A: Physicochemical and Engineering Aspects, vol. 565, pp. 172-179, 2019.

[9] S. Shaji, V. Vinayakumar, B. Krishnan et al., "Copper antimony sulfide nanoparticles by pulsed laser ablation in liquid and their thin film for photovoltaic application," Applied Surface Science, vol. 476, pp. 94-106, 2019.

[10] K. Saravanan, S. Selladurai, S. Ananthakumar, and R. Suriakarthick, "Solvothermal synthesis of copper cadmium sulphide $\left(\mathrm{CuCdS}_{2}\right)$ nanoparticles and its structural, optical and morphological properties," Materials Science in Semiconductor Processing, vol. 93, pp. 345-356, 2019.

[11] M. Akhtar, Y. Alghamdi, J. Akhtar, Z. Aslam, N. Revaprasadu, and M. A. Malik, "Phase controlled synthesis of copper sulfide nanoparticles by colloidal and non-colloidal methods," Materials Chemistry and Physics, vol. 180, pp. 404-412, 2016.

[12] A. Singh, R. Manivannan, and S. Noyel Victoria, "Simple onepot sonochemical synthesis of copper sulphide nanoparticles for solar cell applications," Arabian Journal of Chemistry, vol. 8, pp. 1-9, 2019.

[13] M. R. Hosseini, M. Schaffie, M. Pazouki, A. Schippers, and M. Ranjbar, "A novel electrically enhanced biosynthesis of copper sulfide nanoparticles," Materials Science in Semiconductor Processing, vol. 16, pp. 250-255, 2013.

[14] K. Dobrovolný, P. Ulbrich, M. Švecová et al., "Copper nanoparticles in glycerol-polyvinyl alcohol matrix: in situ preparation, stabilisation and antimicrobial activity," Journal of Alloys and Compounds, vol. 697, pp. 147-155, 2017.

[15] T. Kruk, K. Szczepanowicz, J. Stefańska, R. P. Socha, and P. Warszyński, "Synthesis and antimicrobial activity of monodisperse copper nanoparticles," Colloids Surfaces B Biointerfaces, vol. 128, pp. 17-22, 2015.

[16] L. R. Ferguson, N. Karunasinghe, S. Zhu, and A. H. Wang, "Selenium and its' role in the maintenance of genomic stability," Mutation Research/Fundamental and Molecular Mechanisms of Mutagenesis, vol. 733, no. 1-2, pp. 100-110, 2012.

[17] G. Caroling, M. N. Priyadharshini, E. Vinodhini, A. M. Ranjitham, and P. Shanthi, "Biosynthesis of copper nanoparticles using aqueous guava extract-characterisation and study of antibacterial effects," International Journal of Pharmacy and Biological Science, vol. 5, no. 2, pp. 25-43, 2015.

[18] A. Y. Ghidan, T. M. Al-Antary, and A. M. Awwad, "Green synthesis of copper oxide nanoparticles using Punica granatum peels extract: Effect on green peach Aphid," Environmental
Nanotechnology, Monitoring \& Management, vol. 6, pp. 9598, 2016.

[19] I. Gnanasundaram and K. Balakrishnan, "Synthesis and evaluation of anti-inflammatory activity of silver nanoparticles from Cissus vitiginea leaf extract," Journal of Nanoscience and Technology, vol. 3, pp. 266-269, 2017.

[20] C. Khurana, P. Sharma, O. P. Pandey, and B. Chudasama, "Synergistic effect of metal nanoparticles on the antimicrobial activities of antibiotics against biorecycling microbes," Journal of Materials Science and Technology, vol. 32, pp. 524-532, 2016.

[21] B. H. Patel, M. Z. Channiwala, S. B. Chaudhari, and A. A. Mandot, "Biosynthesis of copper nanoparticles; its characterization and efficacy against human pathogenic bacterium," Journal of Environmental Chemical Engineering, vol. 4, pp. 2163-2169, 2016.

[22] S. S. Shankar, A. Ahmad, R. Pasricha, and M. Sastry, "Bioreduction of chloroaurate ions by geranium leaves and its endophytic fungus yields gold nanoparticles of different shapes," Journal of Materials Chemistry, vol. 13, p. 1822, 2003.

[23] F. Ijaz, S. Shahid, S. A. Khan, W. Ahmad, and S. Zaman, "Green synthesis of copper oxide nanoparticles using abutilon indicum leaf extract: antimicrobial, antioxidant and photocatalytic dye degradation activities," Tropical Journal of Pharmaceutical Research, vol. 16, pp. 743-753, 2017.

[24] F. Elahian, S. Reiisi, A. Shahidi, and S. A. Mirzaei, "Highthroughput bioaccumulation, biotransformation, and production of silver and selenium nanoparticles using genetically engineered _Pichia pastoris_,"Nanomedicine: Nanotechnology, Biology and Medicine, vol. 13, no. 3, pp. 853-861, 2017.

[25] N. Vigneshwaran, A. A. Kathe, P. V. Varadarajan, R. P. Nachane, and R. H. Balasubramanya, "Biomimetics of silver nanoparticles by white rot fungus, _Phaenerochaete chrysosporium_," Colloids and Surfaces B: Biointerfaces, vol. 53, no. 1, pp. 55-59, 2006.

[26] A. Nasser Singab, F. S. Youssef, and M. L. Ashour, "Medicinal plants with potential antidiabetic activity and their assessment," Medicinal \& Aromatic Plants, vol. 3, no. 1, pp. 1-12, 2014.

[27] L. R. Jaidev and G. Narasimha, "Fungal mediated biosynthesis of silver nanoparticles, characterization and antimicrobial activity," Colloids Surfaces B Biointerfaces, vol. 81, pp. 430433, 2010.

[28] H. Y. El-kassas, M. Abd, and E. Okbah, "Phytotoxic effects of seaweed mediated copper nanoparticles against the harmful alga: Lyngbya majuscula," Journal, Genetic Engineering \& Biotechnology, vol. 15, pp. 41-48, 2017.

[29] P. A. Akah, S. U. Uzodinma, and C. E. Okolo, "Antidiabetic activity of aqueous and methanol extract and fractions of Gongronema latifolium (Asclepidaceae) leaves in alloxan diabetic rats," Journal of Applied Pharmaceutical Science, vol. 1, pp. 99-102, 2011.

[30] G. Leelaprakash, S. M. Dass, and B. Road, "Invitro antiinflammatory activity of methanol extract of enicostemma axillare," International Journal of Drug Development and Research, vol. 3, pp. 189-196, 2011.

[31] N. S. Mahabal and B. B. Kaliwal, "In vitro anti-inflammatory activity of L-asparaginase from soil rhizosphere fungus Aspergillus tamarii," Current Trends in Biomedical Engineering \& Biosciences, vol. 4, no. 5, 2017.

[32] J. Y. Kim, S. C. Park, I. Hwang et al., "Protease inhibitors from plants with antimicrobial activity," International Journal of Molecular Sciences, vol. 10, pp. 2860-2872, 2009. 
[33] J. Suárez-Cerda, H. Espinoza-Gómez, G. Alonso-Núñez, I. A. Rivero, Y. Gochi-Ponce, and L. Z. Flores-López, "A green synthesis of copper nanoparticles using native cyclodextrins as stabilizing agents," Journal of Saudi Chemical Society, vol. 21, pp. 341-348, 2017.

[34] K. G. Rao, C. H. Ashok, K. V. Rao, C. S. Chakra, and P. Tambur, "Green synthesis of $\mathrm{TiO} 2$ nanoparticles using aloe vera extract," International Journal of Advanced Research (IJAR), vol. 2, pp. 28-34, 2016.

[35] R. Dobrucka, "Synthesis of titanium dioxide nanoparticles using Echinacea purpurea herba," Iranian Journal of Pharmaceutical Research: IJPR, vol. 16, pp. 753-759, 2017.

[36] P. Ananthi and S. M. J. Kala, "Plant extract mediated synthesis and characterization of copper nanoparticles and their pharmacological activities," International Journal of Advanced Research (IJAR), vol. 6, pp. 13455-13465, 2017.

[37] N. Soni and S. Prakash, "Efficacy of fungus mediated silver and gold nanoparticles against Aedes aegypti larvae," Parasitology Research, vol. 110, pp. 175-184, 2012.

[38] H. Harikrishnan, A. Naif Abdullah, K. Ponmurugan, and R. Shyam Kumar, "Microbial synthesis of selenium nanocomposite using Saccharomyces cerevisiae and its antimicrobial activity against pathogens causing nosocomial," Chalcogenide Letters, vol. 9, pp. 509-515, 2012.

[39] P. Jamdagni, P. Khatri, and J. S. Rana, "Green synthesis of zinc oxide nanoparticles using flower extract of Nyctanthes arbortristis and their antifungal activity," Journal of King Saud University-Science, vol. 30, no. 2, pp. 168-175, 2016.

[40] A. Tovar-Corona, M. A. Lobo-Sánchez, J. L. Herrera-Perez, R. Zanella, J. I. Rodriguez-Mora, and O. Vázquez-Cuchillo, "Green synthesis of copper (0) nanoparticles with cyanidineO-3-glucoside and its strong antimicrobial activity," Materials Letters, vol. 211, pp. 266-269, 2018. 